top ones, and layer formation is prevented altogether above $0 \cdot 15-0 \cdot 2$ per cent sulphuric acid.

Light at temperatures below $10^{\circ}$ slightly reduces the number of layers. At higher temperature no such effect takes place.

Effects on the micro-rings. The formation of microrings is disturbed and eventually prevented with increasing temperature. Alkalinity also has a disturbing influence and above 0.04 per cent sodium hydroxide no micro-rings are formed. Acidity promotes the formation of micro-rings, the optimal concentration being $0 \cdot 02-0 \cdot 12$ per cent sulphuric acid. At higher concentrations their range is reduced and above 0.3 per cent sulphuric acid none is formed.

The most striking influence on the micro-rings is that of light. It is strongly positive and seems to be almost indispensable for their formation. This, however, could not be definitely established; as a few micro-rings near the gelatine surface, have been observed in some experiments conducted in the dark even if the chromate gelatine had been prepared in the red light of a photographic developing lamp. But it is certain that at room temperature, with the concentrations mentioned, no micro-rings are formed more than $20 \mathrm{~mm}$. from the gelatine surface without the action of light. If such an experiment, after having proceeded in the dark for at least twenty-four hours, is exposed to strong light for a limited time, micro-rings are formed beginning from the level to which diffusion has gone. Their formation does not cease when the light is removed but continues in the dark for a period the length of which depends on the intensity of the light and the duration of the exposure.

A chromate gelatine containing 5 per cent gelatine, 0.1 per cent potassium dichromate and 0.03 per cent sulphuric acid was prepared in red light and poured. into test-tubes which were kept in the dark. On the following day, $8 \cdot 5$ per cent silver nitrate solution was poured on top of the set gelatine. After thirty hours the tubes were exposed to various kinds of light with the following results :

\begin{tabular}{|c|c|c|c|}
\hline Light source & $\begin{array}{l}\text { Time of } \\
\text { exposure }\end{array}$ & $\begin{array}{l}\text { Width of belt } \\
\text { of micro-rings }\end{array}$ & $\begin{array}{l}\text { Approx. time } \\
\text { of micro-ring } \\
\text { formation }\end{array}$ \\
\hline $\begin{array}{l}\text { 150-watt bulb at } 50 \\
\text { cm. dist. } \\
\text { Daylight } \\
\text { Daylight } \\
\text { Daylight } \\
\text { Quartz lamp at } 25 \mathrm{~cm} \text {. } \\
\text { dist. } \\
\text { Quartz lamp at } 25 \mathrm{~cm} \text {. } \\
\text { dist. }\end{array}$ & $\begin{array}{l}2 \mathrm{hr} . \\
20 \mathrm{~min} . \\
40 \mathrm{~min} . \\
60 \mathrm{~min} . \\
7 \mathrm{~min} . \\
17 \mathrm{~min} .\end{array}$ & $\begin{array}{l}\text { No micro-rings } \\
\text { No micro-rings } \\
2 \mathrm{~mm} \text {. } \\
3 \mathrm{~mm} \text {. } \\
2 \mathrm{~mm} \text {. } \\
20 \mathrm{~mm} \text {. }\end{array}$ & $\begin{array}{l}-\overline{-} \\
3-\overline{h r} . \\
5-6 \mathrm{hr} . \\
3-4 \mathrm{hr} . \\
2 \text { days }\end{array}$ \\
\hline
\end{tabular}

This after-effect of light can be explained by a photochemical change of the chromate gelatine by which conditions for the formation of micro-rings are produced, and which is slowly reversed in the dark. The change itself also seems to take some time if the light is not very strong. In the case of daylight, not with the quartz-lamp, the micro-rings did not appear immediately upon exposure but 1-2 $\mathrm{mm}$. farther down.

We wish to express thanks to the members of the service scheme of the Agricultural Centre, Heathcot House, Blairs, Aberdeen, for their financial help, which has enabled us to carry out the present work.

${ }^{1}$ Liesegang, Koll. $Z$., 81, 1 (1937). "Chemische Reaktionen in Gallerten"' (Steinkopff, 1924).

'Shemyakin and Michaev, Amer. Chem. Abs., 3662 (1940).

\section{SCIENCE UNDER FASCISM AND DEMOCRACY}

A $\mathrm{T}$ a Conference organized by the Association of A Scientific Workers (West Midland Area) in Birmingham, on August 22, scientific workers from nine nations contrasted the position of science, and scientific workers, in countries under fascist and democratic regimes.

The chairman, Dr. W. Wilson, emphasized that the war effort of the United Nations had depended to a very high degree upon the work of men of science, and if the prosperity and health of the world was to be ensured after the War then the role of the man of science would be no less important. Science, however, can only be expected to flourish in a social and political atmosphere which allows freedom of thought. The Lord Mayor of Birmingham (Councillor W. S. Lewis) tendered a civic welcome to the assembled delegates, and expressed the hope that it would be speedily possible to re-establish the scientific life and culture of the occupied countries in Europe which the Nazis are now trying to destroy.

In a message to the conference, Prof. Semon Sarkisov said that the German invaders had already felt the strength of Soviet science in the blows struck by the Red Army. Thanks to their peace-time achievements, and intensive war-time activity, the men of science had enabled the resources of the Urals, Siberia, and Kazakhstan to be put into effective use for the country's war effort. In the sphere of agriculture they had been able to move successfully a number of essential crops from the Ukraine to the eastern regions of the U.S.S.R. Dr. Goebbels had said : "Humanism, culture, and international law are empty words for us". Was it, then, a wonder that German medical science, for example, had not produced anything new for the benefit of mankind during the period of Nazi rule, but on the contrary it had rapidly declined? Hatred of mankind was the basic feature of fascism, which aimed at enslaving the peoples of the world by using a pseudo-scientific ideology based on the would-be superiority of the German race.

A. van Anrooy (Holland) gave an account of the historical growth of science in Holland under the liberal regimes of the seventeenth and eighteenth centuries, this leading to many famous medieval inventions. The Universities of Leyden and Delft had become famous throughout the world, but under the rule of Seiss Inquart they have been closed and the student organizations disbanded. Dr. C. Koeck, speaking for Austria, outlined the disastrous results upon the scientific life of Vienna of the occupation by the Nazis, since science is merely of secondary importance under fascism.

Prof.J.H. Hildebrand (United States) gave personal impressions of German science gained during visits paid to Germany under the regimes of the Kaiser, Republic, and the Nazis, and instanced many scientific absurdities perpetrated by "Aryan scientists". A totalitarian regime cannot permit any challenge to its power, and the freedom to seek and speak the truth is a danger againist which it must always be suspicious. Benevolent, enlightened despots have been very few. Men of science must add a fifth freedom to their charter: "the freedom to exercise unquenchable curiosity". They must not be bribed by any false promises of political Messiahs who might interfere with their freedom to seek the truth; they 
must insist upon asking questions and getting their answers from Nature rather than from a Dr. Goebbels.

Dr. B. Schober (Czechoslovakia) gave details of the destruction of Czechoslovak scientific culture since Nazi occupation, and the persecution of the students and professors following their resistance to fascist domination. The health of the nation is deteriorating rapidly since the food supplies available provide only one- to two-thirds of the essential calories. Mr. P. M. Yap contrasted the scientific spirit in China and Japan, showing that the Japanese treatment of science follows very closely that of Germany. Full scientific progress in China has been retarded in the past by its dependence upon political and social conditions, but at present these are highly favourable and science is receiving the support of both Government and people. Mr. J. J. Ducenne dealt with the general position of science in Belgium before the War, and then gave impressions of the struggle between men of science and the occupying Nazis.

Prof. J. B. S. Haldane paid a tribute to the scientific workers who had been able to escape from occupied countries and were giving us inestimable help in our destruction of fascism. He then dealt with science in the U.S.S.R., stating that the system of planning had enabled the country to mobilize all men of science for the war effort much more quickly than we could. Planning was done largely by men of science in the U.S.S.R., and it was important to realize that the present power of the Red Army was due to scientific planning in the past, particularly in geological research, which employs some two thousand trained geologists. He thought that undoubtedly the Soviet Union had something to learn from Great Britain regarding liberty; similarly we might learn a lot from the Soviets about planning. It was allimportant that we should learn how to combine planning and freedom, for that was the key problem of the future. It must be realized that scientific workers are skilled manual workers, and we must resist any attempt by educationists to make a gap between the two. The utmost scientific knowledge must be given to ordinary people.

Dr. G. Fournier (France) showed that it was impossible for the man of science to live remote from politics and the affairs of the world. Too many men of science had said : "I am not interested in politics". Now the politicians have become too interested in the men of science, and as a result many had found themselves in custody, and their books burnt. Science has a social value and the man of science cannot wash his hands of his discoveries. It is his duty to see that they are used for the betterment of mankind, and not for its destruction. In future he must be continuously alert to ensure that fascism does not reappear under some other name elsewhere in the world.

Dr. J. G. Siebert (Germany) summed up the discussion, and by resolution the meeting sent its greetings to peoples in subjected countries, and expressed the view that, as rational organization of science for the purpose of waging war would bring victory over the Axis powers, a thorough co-ordination of scientific and technical enterprise could forge weapons to destroy the evils of want, disease, and ignorance which would still have to be confronted when the War was won. The meeting pledged fullest support for "the impending large-scale decisive invasion of the European continent. We call on all scientists and technicians to give of their utmost, whether in workshop or in hospital, in laboratory or at the battlefront".

\section{CIVILIAN CONTRIBUTION TO EDUCATION IN THE FORCES}

7 He Report of the Central Advisory Council for Education in H.M. Forces for the period October 1942-March 1943 again directs attention to the remarkable way in which the project is growing. Much of the increase in demand can be explained by the introduction of compulsory educational periods in the Army during training hours for the months November-February. This not only increased the desire for supplementary lectures by experienced civilians but has, principally in Anti-Aircraft Command, called for aid from the university and university college regional committees in giving the suggested talks on citizenship in a number of small units which do not possess suitable teachers within their ranks. Steps taken by the Royal Air Force, and more recently by the Royal Navy, to encourage the study of current affairs, account for an increase in educational activities by these Services proportionately greater than that for the Army.

There has been an increased demand for lectures and classes by many women's units. Efforts have been made to meet this demand by adding lecturers to regional panels who are particularly well equipped to give the personal approach and treatment of subject which is required by audiences of women. At one A.T.S. conference it was revealed that arranging education in women's units is often more difficult than in men's units, but that the A.T.S. could do much more in the way of education if the right subjects and approach could be found. A profitable introduction to citizenship was being made in women's units through their interest in social services.

An interesting development has been the increase in the number of "site visitors". These are men and women who visit small units at regular intervals to guide and advise units on many social and educational matters. Usually the visit takes the form of an informal talk or discussion and is often followed by requests for help or information in regard to all kinds of group or individual activities. The voluntary organizations connected with education have contributed greatly to the success of these site visits.

People who are interested in the development of residential colleges for adult education for the civilian population will find much to interest them in the short schools and conferenices which were arranged by the regional committees for H.M. Forces. In the period under review, 126 of these courses, etc., were held, 44 of them being residential. They were attended by 4,398 Service men and women, including. members of the U.S. Forces. One of these courses was of three weeks duration and dealt with the basic elements of responsible citizenship, while other courses of the same nature lasted for shorter periods. The experiences gained during these periods of residential study should be of great value to educationists connected with adult work in the post-war period. It should be pointed out that similar courses were arranged for men and women from the Dominions, the fighting services of other members of the United Nations and the merchant navies of Britain and other countries.

The statistics issued in this report show that the number of single lectures given by civilian lecturers. was 61,546 , an increase of 44 per cent over the previous six months. The number of short courses increased 